\title{
ENVELHECIMENTO DA PELE: REFLEXÕES À LUZ DA CORPOREIDADE E DA EMPATIA DE EDITH STEIN
}

SKIN AGING: REFLECTIONS IN THE LIGHT OF EDITH STEIN BODY AND EMPATHY

\author{
Ronny Anderson de Oliveira Cruz ${ }^{1}$ * Francisca das Chagas Alves de Almeida ${ }^{2}$ Bruno Gonçalo Souza \\ de Araújo $^{3}$ * Antonio Carlos Narciso ${ }^{4}$ Xênia Sheila Barbosa Aguiar Queiroz ${ }^{5}$ Marta Mirim Lopes \\ Costa $^{6}$
}

\begin{abstract}
RESUMO
Objetivo: refletir acerca do processo de envelhecimento da pele de pessoas idosas à luz da corporeidade e Da empatia de Edith Stein. Método: Trata-se de um ensaio teórico-reflexivo realizado a partir da busca por artigos, livros, dissertações e teses nos meses de maio e junho de 2021. Resultados: as reflexões deram-se a partir de interpretações da literatura e também de impressões reflexivas dos autores. O texto foi organizado em duas categorias temáticas: "O fenômeno da corporeidade e o processo de envelhecimento da pele de pessoas idosas" e "A empatia como tecnologia leve em atenção a pessoas idosas que vivenciam o envelhecimento da pele". Considerações finais: Esta reflexão possibilitou aproximar os conceitos de corporeidade e empatia de Edith Stein em relação ao modo como percebe-se o corpo e a pele envelhecida. Espera-se que os enfermeiros em seus diversos cenários de atuação possam estimular o uso da empatia como instrumento de recondução/reconstrução sobre o olhar que se tem a respeito da pele envelhecida de pessoas idosas.
\end{abstract}

Palavras-chave: Empatia; Envelhecimento da pele; Imagem corporal; Saúde do Idoso.

\begin{abstract}
Objective: to reflect on the aging process of the skin of elderly people in the light of the corporeity and Empathy of Edith Stein. Method: This is a theoretical-reflective essay carried out from the search for articles, books, dissertations and theses in the months of May and June 2021. Results: the reflections were based on interpretations of the literature and also impressions reflections of the authors. The text was organized into two thematic categories: "The phenomenon of corporeality and the aging process of the skin of elderly people" and "Empathy as a light technology in attention to elderly people who experience skin aging". Final considerations: This reflection made it possible to bring together Edith Stein's concepts of corporeality and empathy in relation to the way in which aging skin and body are perceived. It is expected that nurses in their different work scenarios can encourage the use of empathy as an instrument of renewal/reconstruction of the look that one has regarding the aged skin of elderly people.
\end{abstract}

Keywords: Empathy; Aging of the Skin; Body Image; Health of the Elderly.

\footnotetext{
${ }^{1}$ Enfermeiro pela Universidade Federal da Paraíba, Doutorando em Enfermagem Pelo Programa de Pós-graduação em Enfermagem da Universidade Federal da Paraíba, Docente do Centro Universitário de João Pessoa - UNIPÊ, João Pessoa, Paraíba, Brasil. ORCID: https://orcid.org/0000-0001-6443-7779

${ }^{2}$ Enfermeira pela Universidade Federal da Paraíba, Doutoranda em Enfermagem Pelo Programa de Pós-graduação em Enfermagem da Universidade Federal da Paraíba, Docente do Centro Universitário de João Pessoa - UNIPÊ, João Pessoa, Paraíba, Brasil. ORCID: https://orcid.org/0000-0001-7519-1292

${ }^{3}$ Enfermeiro pelo Centro Universitário de João Pessoa - UNIPÊ, Mestrando em Enfermagem Pelo Programa de Pós-graduação em Enfermagem da Universidade Federal da Paraíba. João Pessoa, Paraíba, Brasil. ORCID: https://orcid.org/0000-0002-4124-6061

${ }^{4}$ Enfermeiro pela Faculdade Santa Emília de Rodat, Mestre em Enfermagem Pelo Programa de Pós-graduação em Enfermagem da Universidade do Estado de Pernambuco, Docente do Centro Universitário de João Pessoa - UNIPÊ, João Pessoa, Paraíba, Brasil. ORCID: https://orcid.org/0000-0002-0446-756X

${ }^{5}$ Enfermeira pela Universidade Federal de Campina Grande, Doutoranda em Enfermagem Pelo Programa de Pós-graduação em Enfermagem da Universidade do Estado de Pernambuco, Enfermeira do Hospital Regional de Urgência e Emergência Dom Luiz Gonzaga Fernandes, Campina Grande, Paraíba, Brasil. ORCID: https://orcid.org/0000-0003-3218-4759

${ }^{6}$ Enfermeira pela Universidade Federal da Paraíba, Doutora em Sociologia Pelo Programa de Pós-graduação em Sociologia da Universidade Federal da Paraíba, Docente da Graduação e Pós-graduação em Enfermagem da Universidade Federal da Paraíba, João Pessoa, Paraíba, Brasil. ORCID: https://orcid.org/0000-0002-2119-3935
} 


\section{INTRODUÇÃO}

O desejo de aumentar a expectativa de vida sempre foi um anseio presente nas diversas sociedades. As mudanças do perfil da população idosa são visíveis a partir da observação da pirâmide etária brasileira. De modo que, tanto no Brasil quanto em outros países, têm-se constatado implicações que vão além das alterações no quadro demográfico, o que tem imbricado em reflexões e tomadas de decisão para o cuidado dessa população específica em um futuro bem próximo ${ }^{(1)}$.

Assim, frente às alterações que ocorrem durante o processo de envelhecimento destacam-se àquelas inerentes à pele, estrutura que recobre e protege todo o corpo e apresenta-se como um órgão complexo que compreende $15 \%$ do peso corporal, neste também acontecem interações celulares e moleculares importantes, as quais são responsáveis por declínio progressivo na capacidade proliferativa e no tempo de vida das células, ao considerar-se o contexto da pessoa idosa. Estudos revelam que mais de 90\% dos idosos apresentam algum tipo de distúrbio na pele entre eles, a xeroxe cutânea, o fotoenvelhecimento, o câncer de pele, as lesões por pressão e outros agravos, cuja incidência e prevalência aumentam com o passar da idade ${ }^{(2)}$.

A pele seca ou xerose cutânea apresenta-se como uma modificação do estrato córneo caracterizada por proliferação e diferenciação prejudicada de queratinócitos, conteúdo lipídico, hidratação, potencial hodrogeniônico $(\mathrm{pH})$ e produção de sebo. Em pessoas idosas, a xerose é resultante da diminuição na hidratação da superfície da pele e do consequente aumento da perda de água transepidérmica. Comumente tratada como xerose senil, é um dos problemas dermatológicos mais prevalentes, atingindo cerca de $30 \%$ a $58 \%$ das pessoas idosas ${ }^{(3)}$.

Estas alterações tanto retratam o comprometimento físico, mas podem também desvelar as consequências psicológicas como em estudo realizado pelos autores ${ }^{(4)}$, onde a pessoa idosa compreende como objeto a imagem corporal a partir das alterações senescentes como significado negativo no envelhecer, onde salientam o enrugamento de pele e a velhice como algo difícil. Foi ainda percebido o desejo de ter um corpo físico jovial nos resultados, o que distancia o olhar da pessoa idosa para si como ser em totalidade, como sujeito da percepção diante do mundo.

Para a autora $^{(5)}$, Körper (corpo físico) refere-se aos aspectos estritamente materiais e físicos do corpo, daquilo que ele tem em comum com todos os objetos do mundo, abstraindo, portanto, da sua conexão com uma consciência. Leib (corpo vivo), por outro lado, é o corpo enquanto algo vivo, animado por uma "alma" e que envolve todos os aspectos psicológicos da consciência $^{(5)}$. 
A fenomenóloga explica que o corpo vivo constitui-se de uma maneira dupla, enquanto Leib, senciente (percebido corporalmente) e enquanto Körper do mundo externo, percebido assim externamente, e nessa dupla apresentação é vivenciado como o mesmo. Essa constituição dupla do corpo implica que embora possamos em teoria, abstrair da sensação vivenciada no corpo vivo e percebê-lo apenas enquanto corpo físico, ou seja, enquanto objeto "externo", tal análise é em certo sentido artificial, pois é impossível abrir mão da faculdade senciente de nosso próprio corpo $^{(6)}$.

Sendo Edith Stein frequentadora do círculo de fílósofos da fenomenologia, passou a ser assistente de Edmund Husserl e concordava com seu mentor por meio do reconhecimento de após a realização da epoché fenomenológica ocorre a permanência da consciência que o "eu" tem dos outros "eus-sujeito", assim como, a constatação de que existe a ser compartilhado e comunicado entre todos um mundo comum. Nesse sentido, compreende-se a consciência de que todo "eu", tem a condição de experienciar a vida psíquica alheia e comum a sua, por meio da empatia. A empatia segundo Stein, possibilita o exercício humano de conhecer e compreender melhor o outro, a partir da intersubjetividade, conceito fundamental para o entendimento das relações humanas e também para orientar o nosso comportamento frente ao outro ${ }^{(7,8)}$.
É digno de nota o fato de Stein enfatizar que a apreensão do corpo de outras pessoas complementará a apreensão da corporeidade própria, uma vez que como ponto inicial de análise, a própria pessoa possui, por princípio, limites para a apreensão de sua corporeidade ${ }^{(9)}$. Assim este ensaio tem como objetivo refletir acerca do processo de envelhecimento da pele de pessoas idosas à luz da corporeidade e da empatia de Edith Stein.

\section{MÉTODO}

Trata-se de um ensaio teóricoreflexivo que se fundamentou com base na fenomenologia de Edith Stein no tocante a temática da corporeidade e da empatia em relação ao processo de envelhecimento cutâneo. Foi realizado de modo sistemático durante os meses de maio e junho de 2021, uma busca por artigos, livros e documentos por meio das palavras "corporeidade", "empatia", "pele envelhecida", "pessoa idosa", "envelhecimento" e "fenomenologia" que foram cruzadas por meio do operador booleano and enquanto estratégia de busca nas bases Literatura Latino-Americana e do Caribe em Ciências da Saúde (LILACS), Base de Dados de Enfermagem (BDENF), EBSCOhost Research Platform e Medical Literature Analysis and Retrieval System Online (MEDLINE). Salienta-se que ainda foram consultadas teses e dissertações por 
meio do Banco de Teses e Dissertações (BTD) da Coordenação de Aperfeiçoamento de Pessoal de Nível Superior (Capes) em programas de pós-graduação em filosofia.

A apresentação das explanações e reflexões deu-se a partir de interpretações da literatura e também, impressões reflexivas dos autores. O texto foi organizado em duas categorias temáticas: "O fenômeno da corporeidade e o processo de envelhecimento da pele de pessoas idosas" e "A empatia como tecnologia leve em atenção a pessoas idosas que vivenciam o envelhecimento da pele".

\section{O fenômeno da corporeidade e o processo de envelhecimento da pele em pessoas idosas}

Edith Theresa Hedwing Stein nasceu em 12 de outubro de 1891 na cidade de Breslau, Alemanha, sendo uma das mais fiéis discípulas de Edmund Husserl. Tornou-se monja no Carmelo de Colônia recebendo o nome de Teresa Benedita da Cruz, com 42 anos. Foi canonizada Santa pela igreja católica pelo Papa João Paulo II assumindo os títulos de filósofa, teóloga, e mártir, pois em 02 de agosto de 1942 foi presa e no dia 09 morreu na câmara de gás no campo de extermínio nazista em Auschwitz ${ }^{(10)}$.

Seus escritos místicos trazem o contexto do diálogo entre a filosofia de São Tomás de Aquino e a fenomenologia Husserliana, onde procurou valorizar e afirmar a grandeza subjetiva no humano reconhecendo sua potencialidade. Ainda ressaltou a importância em se compreender o homem pela fenomenologia partindo do princípio da atenção as coisas nelas mesmas, princípio este, que possibilita a aproximação da experiência humana de tal forma que se possa "dirigir o olhar ao essencial" liberando a intuição, no sentido específico de Husserl como um ato de percepção espiritual que capta a essência ${ }^{(10,11)}$.

A fenomenóloga compreende o ser em três aspectos: corporeidade, alma e espírito e ressalta a importância sobre a consciência de si mesmo. A corporeidade significa o corpo vivo em sua relação com o corpo físico, corpo vivo vinculado a um sujeito, como corpo vivo que sente, corpo organismo vivo, corpo vivo e vontade, corpo e expressão ${ }^{(12)}$.

Durante o processo de redução, observa-se as sensações como um dos componentes efetivos da consciência em que se apresenta como uma categoria superior de vivência. Mesmo sem emanar do eu puro, nunca adota a forma do cogito ao mesmo tempo em que se encontra fundida no corpo vivo. $\mathrm{O}$ corpo vivo manifesta-se a consciência do sujeito a todo momento, sobretudo por meio da percepção externa através dos sentidos do tato e da visão, e nesse sentido, se evidencia-se como sua pertença, ou seja, como parte do si mesmo. Segundo Stein o próprio corpo percebido externamente consistirá apenas em um corpo físico, 
classificado, singularizado, no entanto nunca o próprio corpo vivo ${ }^{(8)}$.

Esse mesmo corpo apresenta-se como um objeto que é dado em uma sequência de aparições que estará em sintonia constantemente. Pois ao perceber o corpo, esta se dá de modo senciente de um corpo próprio. Além disso, esse desvelar ocorre em meio as abstrações constituídas por si na percepção deste corpo próprio.

Importante faz-se destacar que, para Edith Stein, a presença da corporeidade viva é o fundamento para o conhecimento a respeito das pessoas humanas. Não se pode prescindir, portanto, da descrição dessa estrutura para a análise da pessoa enquanto objeto do conhecimento, mas também como sujeito do mesmo - a pessoa conhece outras pessoas, seu mundo externo e interno, a partir de sua corporeidade $^{(9)}$.

Comumente o corpo envelhecido é interpretado por meio da valorização das alterações senescentes e nesse prisma todo arcabouço negativo do envelhecer. As mudanças da pele representam a imagem primeira que na ausência de uma redução é objetivamente formada como enrugada, fina, seca e frágil. A esta imagem vincula-se o desejo do regressar ao corpo físico jovial, o que parece ter se tornado prioridade ao compara-se com a experiência de voltar-se a si, como ser em totalidade, como sujeito em um contexto de completude, de existência e de ser no mundo.
A fragilidade da velhice quando se compara o corpo habitual (rememoração do corpo físico jovem) com o corpo atual (pessoa idosa), tem caracterizado-se como ponto de interferência e possível de contribuição ao refletir acerca da valorização da pessoa idosa enquanto ser no mundo, sobretudo por meio de construções intersubjetivas levando a ressignificação no tocante a compreensão das mudanças ocasionadas na pele e do corpo envelhecido ${ }^{(4)}$.

No entanto, Stein alerta sobre a possibilidade de limites e de enganos ao apreendermos a expressão do outro, captada por meio das mudanças em sua corporeidade, já que a experiência vivida pelo outro possui limites, uma vez que a expressão do outro, verbal ou não verbal, pode ser resultado de uma decisão que esconda os sentidos e os motivos vivenciados pelo sujeito da experiência. A certeza desse conhecimento apenas pode ser atingida na medida em que o outro expresse o sentido de suas ações e nos dê acesso à sua interioridade. Pode-se intuir que, em cada ação alheia, algo de seu núcleo pessoal possa estar sendo expresso, mas o reconhecimento seguro dessa expressão não garante a previsão dos comportamentos alheios. Dar-se a conhecer em sua profundidade é um ato de liberdade e não pode ser violado sem seu consentimento ${ }^{(13)}$.

A partir do momento em que o "eu transcendental" ou o "eu puro" da pessoa idosa concebe imanimente o corpo 
fenomenológico como mediador da relação do homem com o mundo é capaz de desdobrar-se sobre a intersubjetividade e a intencionalidade $^{(14)}$, e assim, a experiência perceptiva do sujeito surge mediante a sua presença enquanto corpo no mundo, de tal forma $o$ alcance da compreensão do envelhecimento cutâneo para além do olhar diante dos julgamentos, das limitações e perdas, o que possibilitaria considerar-se sujeito de sua própria história, por meio do autoconhecimento e valorização do seu corpo e assim de sua corporeidade.

\section{A empatia como tecnologia leve em atenção}

a pessoas idosas que vivenciam o envelhecimento da pele

A empatia passou a ser discutida no campo das neurociências por volta da década de 1990 com a descoberta dos "neurôniosespelho". Esse passou a ser a base da compreensão para o comportamento empático, onde o sofrimento dos outros é reconhecido e respondido cognitivamente e afetivamente de forma imediata. As pesquisas na área têm se tornado cada vez mais significativas a partir da descoberta e comprovação da empatia como um processo também neurofisiológico, e com isso, inclinando-se para temáticas inerentes ao processo de facilitação de aprendizagem, qualificação de relações interpessoais e redes de apoio, e desenvolvimento de outros construtos positivos, como resiliência, tolerância e esperança ${ }^{(15,16)}$.

$$
\text { A "Empatia" (Einfühlung), para }
$$

Edmund Husserl, é uma vivência essencial de compreensão entre as pessoas que objetivam o conhecimento. Para o autor ${ }^{(17)}$, Husserl compreendia a empatia como a forma de conhecimento pela qual o ser humano deve reconhecer o outro e suas vivências, até chegar à descrição eidética das vivências puras.

A empatia segundo a autora $^{(5)}$, fundamente-se no exercício humano de conhecer e compreender melhor o outro por meio da intersubjetividade. Em seus escritos, a filósofa reitera que $\mathrm{o}$ ato de empatia concretiza-se no aqui e agora executado pelo sujeito, e permite reconhecer ou outro de modo único e singular na experiência vivenciada. Assim, é então percebida como um ato de conhecimento da estrutura do ser humano em sua integridade, mas também pode contribuir para a efetivação de relações éticas $^{(8)}$

Edith Stein atuou como voluntária da cruz vermelha no hospital de Mährisch Weißkirchen, período em que suas inquietações sobre a empatia afloraram. Vislumbrava a instituição como uma entidade cosmopolita cercada de fenômenos sociais, e assim também propunha uma leitura fenomenológica de grupos sociais, já que afirmava que o homem realiza atos sociais, é membro de estruturas sociais, mantêm 
relações sociais consequentemente é um tipo social. Nesse ínterim concebe a empatia como fenômeno pluralista ${ }^{(18)}$.

As tecnologias são divididas em três categorias enquanto tecnologias leves (comunicação, acolhimento, vínculo e escuta), tecnologias leves duras (epidemiologia, clínica e outras com saberes estruturados) e as tecnologias duras (equipamentos e máquinas, material utilizado no ato de cuidado em saúde $)^{(19)}$.

A empatia enquanto tecnologia leve para o cuidado é capaz de auxiliar na construção das relações entre o ser-cuidador e o ser-cuidado, sendo esta materializada entre a pessoa idosa e o enfermeiro, mas vai além e possibilita ainda, uma relação com outras pessoas idosas e mediada pela confiança através da comunicação, escuta e acolhimento.

Assim, as pessoas idosas sentem, percebem e perpetuam entre si, uma infinidade de conceitos formulados com base nos aspectos considerados como "negativos" ou limitantes acerca do processo de envelhecimento e sendo a pele o maior órgão e o mais exposto costuma a ser sempre considerado. Nesta compreensão, a autora ${ }^{5}$ descreve que quanto mais a comunidade envolve o indivíduo no seu "mecanismo" e o conforma ao seu tipo, maior é o perigo de que a natureza individual deste venha inibida no seu desenvolvimento, o que possibilita sua manutenção. Em contrapartida, quando a força com a qual a natureza individual desenvolve-se é maior, mais cresce a percepção de que a comunidade é muito estreita para o indivíduo, e com isso, ele termine por separar-se intimamente e talvez também exteriormente. No entanto, a filósofa aponta que o pertencimento que toda pessoa pode ter com a comunidade, ou seja, à vida social e cultural, também comporta uma consciência e responsabilidade que parte de cada indivíduo particular para que assim, a vida comunitária possa tornar-se bela e prazerosa, e esse alcance conquistado por meio de valores e da ética ${ }^{(20)}$.

Stein compreende que a vida em comunidade dá-se pela construção de várias pessoas, cada qual com suas vivências individuais, em contrapartida, a vida em comunidade também é útil e necessária para a formação da pessoa, pois a governa para um conhecimento mais amplo e coerente de si mesma, do outro e do mundo. É na convivência pessoal que se dá o processo de empatizar, que colabora para que a pessoa forme-se plenamente, podendo desenvolver todas as suas potencialidades humanas e sociais $^{(21)}$.

É digno notar que Stein amplia o escopo das análises sobre a empatia ao investigar a experiência de mútua compreensão, com tudo que isso envolve: reconhecimento da outra pessoa em seus aspectos físicos e psíquicos, bem como a verificação de como isso interfere no próprio 
entendimento do eu. Assim ao referir-se a experiência de empatia como a percepção do sujeito alheio como algo que não pode ser mero corpo físico, a filósofa explicita que a experiência de outros sujeitos surge de uma vivência que denomina de "cooriginaridade" (Konoriginarität). Não se trata de uma experiência originária, pois essa só é dada diretamente, nas "vivências próprias" imediatas e atualmente presentes, como o experienciar direto, por exemplo, do movimento do próprio corpo a partir de um ato de vontade. É possível, claro, conceber os sujeitos alheios enquanto meros objetos físicos, mas essas seriam considerações secundárias e particulares, em certo sentido derivadas da experiência mais imediata. De modo direto, o vivenciar de outros sujeitos já envolve essa percepção de tratar-se de um sujeito semelhante a mim, e, portanto, o corpo alheio é visto como corpo vivo ${ }^{(6)}$.

Ao vislumbrar contribuir com modificações acerca das vivências das pessoas idosas sobre suas concepções relacionadas ao processo de envelhecimento da pele, Edith Stein apresenta um dos aspectos mais relevantes da experiência empática que se trata da projeção da "imagem alheia do mundo" que torna capaz de gerar uma "modificação" na própria concepção. Segundo ela, a imagem do mundo que eu empatizo como sendo do outro é capaz de modificar a minha própria imagem em função da condição de corpo vivo(5).
Assim, com a experiência empática de vivenciar como é o mundo desde a perspectiva do outro, projeto olhares que não estariam dados do meu ponto de vista atual. E, assim, a possibilidade do enriquecimento da própria imagem do mundo através da imagem dos outros, e a relevância da empatia para a experiência do mundo externo real como alternativa no processo de reorientação de uma visão "negativa" para uma de acolhimento, compaixão e empatia.

\section{CONSIDERAÇÕES FINAIS}

Esta reflexão possibilitou aproximar os conceitos de corporeidade e empatia de Edith Stein em relação ao modo como percebe-se o corpo e a pele envelhecida. Esta imagem tem-se vinculado ao desejo de regressar ao corpo físico jovial sem conceber uma experiência que possibilitaria considerarse sujeito de sua própria história, por meio do autoconhecimento e valorização do seu corpo e assim de sua corporeidade.

A empatia segundo Stein visa uma melhor compreensão do outro por meio da intersubjetividade que pode influenciar em modificações no próprio ser. Trata-se de um ato de conhecimento da estrutura do ser humano em sua integridade e que, ao ser experienciada, é possível modificar internamente e reorientar a visão sobre alguns fenômenos. Espera-se que esta reflexão possa contribuir com um novo olhar de enfermeiros em seus diversos cenários de atuação, para 
que assim possam estimular o uso da empatia como instrumento

de recondução/reconstrução do processo de cuidado no tocante à pele envelhecida de pessoas idosas não apenas no que se refere aos aspectos técnicos, mas que possam ir além vislumbrando o cuidado de modo integral e humanizado.

\section{REFERÊNCIAS}

1. Dantas IC, Júnior EPP, Medeiros KKAS, Souza EA. Perfil de morbimortalidade e os desafios para a atenção domiciliar do idoso brasileiro. Rev Kairós [Internet]. 2017; [acesso em 2 jun 2021]; 20(1):93$108 . \quad$ Disponível em: https://doi.org/10.23925/2176901X.2017v20i1p93-108

2. Sá SPC, Brandão ES, Camacho ACLF, Oliveira BGRB, Caldas CP. Interfaces da Enfermagem Dermatológica e Gerontológica na Prevenção de Lesões por Pressão: uma Reflexão. ESTIMA, Braz. J. Enterostomal Ther. [Internet]. 2016; [acesso em 2 mai 2021]; 14(4):e0421. Disponível em: https://www.revistaestima.com.br/estima/ article/view/436

3. Melo MA, Campos PMBGM. Técnicas para avaliar a hidratação e a oleosidade da pele. Cosmet. toiletries. [Internet]. 2016; [acesso em 2 mai 2021]; 28(2):30-4. Disponível em: https://www.cosmeticsonline.com.br/ct/pa inel/class/artigos/uploads/0b33c282_EdMar_Abr-2016.pdf

4. Almeida L, Bastos PRHO. O desvelar do significado do corpo envelhecido para o idoso: Uma compreensão fenomenológica. Rev Espacios. [Internet]. 2017; [acesso em 6 mai 2021]; 38(29):23-31. Disponível em: https://www.revistaespacios.com/a17v38n 29/a17v38n29p23.pdf

5. Stein E. Zum Problem der Einfühlung. Freiburg/Basel/Wien: Herder; 2008.

6. Missagia J. Sobre a originalidade de Edith Stein: o papel da distinção entre Körper (corpo físico) e Leib (corpo "vivo") para a empatia e a constituição do eu. Rev. Filos. [Internet]. 2017; [acesso em 10 mai 2021]; 29(48):799-818.

$\underline{10.7213 / 1980-}$ 5934.29.048.DS06

7. Gracioso J, Parise MCI. Eu puro e empatia segundo Edith Stein. Argum Rev Filos. [Internet]. 2018; [acesso em 10 mai 2021]; 9(18):60-73. Disponível em: http://www.periodicos.ufc.br/argumentos/ $\underline{\operatorname{article} / v i e w / 31028}$

8. Grzibowski S, Barea R. Empatia e Ética na fenomenologia de Edith Stein. Ágora Filos. [Internet]. 2015; [acesso em 10 jun 2021]; $15(1): 34-46$. https://doi.org/10.25247/P1982999X.2015.v1n2.p34-46

9. Cardoso CRD, Massimi M. A corporeidade segundo Edith Stein: algumas implicações para a psicologia. Interam. j. psychol. [Internet]. 2018; [acesso em 10 jun 2021]; 52(1):71-9. https://doi.org/10.30849/rip/ijp.v52i1.124

10. Monteiro FSCT, Reis CES, Albuquerque CVE, Santos VLM dos, Gomes AC, Vieira $M$ de $S$. Possíveis propostas fenomenológicas de Edith Stein na promoção de saúde. Cad Bras Saúde Ment. [Internet]. 2018; [acesso em 10 jun 2021]; 10(27):157-64. Disponível em: https://periodicos.ufsc.br/index.php/cbsm/ article/view/69227

11. Queiroz MIC. O percurso pela noção de força em Edith Stein. Argum Rev Filos. [Internet]. 2018; [acesso em 12 jun 2021]; 9(18):18-33. Disponível em: 
http://www.periodicos.ufc.br/argumentos/ article/view/31025/71644

12. Coelho KGS. A liberdade na relação indivíduo e comunidade segundo Edith Stein. [Dissertação]. Fortaleza: Universidade Estadual do Ceará; 2012. $107 \mathrm{p}$.

13. Júnior AGC, Barreira CRA. Formação da personalidade autêntica e corporeidade à luz de Edith Stein. Psicol. USP. [Internet]. 2018; [acesso em 14 jun 2021]; 29(3):34553.

Disponível em: http://www.scielo.br/scielo.php?script=sci _arttext\&pid=S0103$\underline{65642018000300004 \& \operatorname{lng}=\text { en } \& n r m=i s o}$

14. Merleau-Ponty M. Fenomenologia da Percepção. 4ed. São Paulo: Martins Fontes; 2011.

15. Brolezzi AC. Empatia em Vygotsky. Dialogia. [Internet]. 2014; [acesso em 14 jun 2021]; 20(2):153-66. Disponível em: https://periodicos.uninove.br/dialogia/artic le/view/4944/2843

16. Medeiros AGAP, Júnior JASH. Empatia em Idosos como processo multifacetado. Rev. Diálogos. [Internet]. 2017; [acesso em 18 jun 2021]; 18(1):43-63. Disponível em:

http://www.revistadialogos.com.br/Dialog os_18/Dial_18_Gabriel_Spencer.htm

17. Barea R. O tema da empatia em Edith Stein. Porto Alegre: Editora Fi; 2016.
18. Ferreira DS. Empatia: uma história intelectual de Edith Stein 1891- 1942. [Dissertação]. Ouro Preto: Universidade Federal de Ouro Preto; 2018. 157 p.

19. Almeida Q, Fófano GA. Tecnologias leves aplicadas ao cuidado de enfermagem na unidade de terapia intensiva: uma revisão de literatura. HU Rev. [Internet]. 2016; [acesso em 14 jun 2021]; 42(3):2016. Disponível em: https://periodicos.ufjf.br/index.php/hurevi sta/article/view/2494

20. Cruz RAO, Almeida FCA, Agra G, Costa MML. Enlaces entre cuidado y empatía a partir de una reflexión steiniana en tiempos de pandemia. Rev Cubana Enferm [Internet]. 2020; [acesso em 19 jun 2021]; 36(e4028p):1-10. Disponível em: http://www.revenfermeria.sld.cu/inde x.php/enf/article/view/4028

21. Cruz MP. Pessoa, comunidade e empatia em Edith Stein. [Dissertação]. Brasília: Universidade de Brasília; 2018. 84 p.

\section{Autor correspondente}

Ronny Anderson de Oliveira Cruz

Rua Dom Pedro II, 17, Tibirí, Santa Rita - PB

CEP: $58300-660$

Telefone: +5583 98748-0341

e-mail: ronnyufpb@gmail.com

Submissão: 2021-09-01

Aprovado: 2021-10-14 